\title{
"No no no" and Other Types of Multiple Sayings in Social Interaction
}

\author{
TANYA STIVERS \\ Max Planck Institute
}

\begin{abstract}
Relying on the methodology of conversation analysis, this article examines a practice in ordinary conversation characterized by the resaying of a word, phrase, or sentence. The article shows that multiple sayings such as "No no no" or "Alright alright alright" are systematic in both their positioning relative to the interlocutor's talk and in their function. Specifically, the findings are that multiple sayings are a resource speakers have to display that their turn is addressing an in progress course of action rather than only the just prior utterance. Speakers of multiple sayings communicate their stance that the prior speaker has persisted unnecessarily in the prior course of action and should properly halt course of action.
\end{abstract}

If I was told anything that was a theory, I would say, "No, no! That does not interest me."-Ludwig Wittgenstein

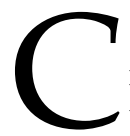

onversation analytic researchers across the disciplines of communication, linguistics, and sociology have, for more than 30 years, worked to describe and explicate "the competences that ordinary speakers use and rely on in participating in intelligible, socially organized interaction" (Heritage \& Atkinson, 1984). Social interaction requires that many different practices and systems of practices be brought together; however, each is part of the puzzle and provides another glimpse into the mechanics of interpersonal communication. In Goffman's terms, each interactional practice is another "animal ... in the interactional zoo" (1983, p. 6). To this end, this paper describes the defining features of, and

Tanya Stivers works for the Max Planck Institute for Psycholinguistics. A portion of this paper was presented at the National Communication Association Convention in Atlanta, GA in November, 2001 and at the Western States Communication Association Convention in Salt Lake City, UT in February, 2003. The author thanks Galina Bolden and Makoto Hayashi for particularly helpful examples and John Heritage, Gene Lerner, Jeff Robinson, and Manny Schegloff for advice and insight. Correspondence concerning this article should be addressed to Tanya Stivers, Max Planck Institute for Psycholinguistics, PB 310, 6500 AH Nijmegen, The Netherlands; email: Tanya.Stivers@mpi.nl.

Human Communication Research, Vol. 30 No. 2, April 2004 260-293

(C) 2004 International Communication Association 
analyzes the functions of, another of these "animals" - multiple sayings in a speaker's talk.

It is readily observable that speakers in conversation commonly repeat parts of their utterances (e.g., Schegloff, 1987; Tannen, 1989; Wong, 2000). Some researchers have focused on utterance repetition as a dysfluency (e.g., Clark \& Wasow, 1998; Shimanoff \& Brunak, 1977); within the theoretical framework that interactants are systematic in the way that they produce and respond to talk, repeated words and other types of re-sayings are more accurately understood as comprising discrete interactional practices, each of which communicates something quite different. This article identifies one practice as "multiple sayings." Specifically, this practice involves a speaker repeating some unit of talk (e.g., whether a word, phrase, or sentence) in the same turn, multiple times, under a single intonation contour, such as "No no no." or "Wait wait wait.". This article will first describe the practice and then discuss its communicative function.

Multiple sayings specifically have the following five features: They (a) involve a full unit of talk being said multiple times, (b) are said by the same speaker, (c) have a similar segmental character, ${ }^{1}$ (d) happen immediately in succession, and (e) are done under a single intonation contour. A number of researchers have examined repeated utterances by the same speaker in conversation; however, existing studies are only tangentially related to the communication practice being discussed here. For example, Tannen (1989) explored the pervasiveness of a range of phenomena that involve the recurrence or collocation of words. Rather than examining a systematic interactional practice involving repetition, she examined a range of practices that share in common the feature of repetition. Conversation analytic research on same speaker repetition has involved the domains of repair (Schegloff, Jefferson, \& Sacks, 1977); restarting turns, as in overlapping talk (Schegloff, 1987); connecting back to something that had been started previously (Wong, 2000); and sequence closing (Schegloff, 1995). ${ }^{2}$ Instances of the practice of multiple sayings have appeared in data extracts shown in research papers, but these instances have not been systematically analyzed as a practice in its own right. For example, Schegloff (1992) mentioned that third-position-repair commonly involves the token "no," singly or in multiples, as a repair initiator. Müller (1996) showed an instance in French of "Oui oui oui" and asserts that in contrast to a single token "yes," the repeated "oui" constitutes a "stronger" recognitional (p. 135). This study argues that multiple sayings are not simply upgrades on the single token. In fact, at times the interactional work being done by the repeating of the item may be at odds with the work being done by the single item (see Extract 4 as an example). This will be taken up in more detail in the next section of the paper. 
A key feature of multiple sayings is that they are produced as a single turn constructional unit (Sacks, Schegloff \& Jefferson, 1974) under a single intonation contour, rather than each item of the saying comprising its own independent contour. A number of researchers have shown prosody to be a key resource for interactants in their analyses of turns in progress and, in particular, for enabling interactants to project a transition relevance place, thereby facilitating the system of turn taking as outlined by Sacks, Schegloff, and Jefferson (1974) (Chafe, 1980; Duncan \& Fiske, 1977; Ford, 1993; Ford \& Thompson, 1996; Levelt, 1989). Research on units of intonation has shown a high convergence between intonation (i.e., final intonation) and syntactic unit completion (Ford \& Thompson, 1996). Levelt (1989) acknowledged that "an intonational phrase can cross a sentence boundary;" however, he indicated that this is quite rare.

Intonation contours provide speakers with an additional resource for managing turn transition. Specifically, a stretch of talk can be delivered as a single prosodic package brought to a single point of completion, or it can be delivered as involving multiple packages each of which involves a type of final intonation point. For example, a repeat of the item "Okay" can be said and transcribed as "Okay. Okay. Okay." or alternatively as "Okay okay okay." In the former, each item "Okay." comes to falling period intonation. By contrast, in the latter example, each item "Okay" is part of a single intonation contour not coming to period intonation until following the third saying of "okay."

Units of intonation have been identified using a number of different terms, including "intonational phrases" (e.g., Pierrehumbert, 1980), "intonation units" (e.g., Schuetze-Coburn, Shapley \& Weber, 1991), "tone units" (e.g., Crystal \& Quirk, 1964), and "intonation contours" (e.g., Chafe, 1987). This article refers to an "intonation contour," as the focus is the way a unit of talk has a particular intonational trajectory or shape from its outset. Broadly described, the sound production of the multiples can be characterized as beginning at a slightly higher pitch and being produced without a break in phonation and with a gradual and steady fall until they reach final intonation. This contour appears to be hearable from the outset of the multiple saying (see Couper-Kuhlen, 2001 for a related discussion of pitch onset). This contour is critical since interactants treat repeated items differently depending on their prosody. For instance, in the extract below, a doctor has just suggested using a dandruff shampoo on the child. In line 1, the doctor again refers to the shampoo ("tha:t,") and instructs the mother in what to do with the boy's flaky skin. In response to this instruction, the mother reuses the token "Right" to acknowledge the doctor's explanation of how to deal with her child's dandruff. 
(1) 2023 ((Transcription symbols used in all data are shown in Appendix A))

1 DOC: .h Use tha:t, an:' when you see thuh: thing-sw-

2 wị:pe it off. scrape it off [like that.]

3 MOM:-> [ Ri:ght. ] R[ight.

4 DOC: [Okay?

5 MOM:->Right.

6 DOC: And the::n, uhm if you see like thuh redness,

7 like infected?, [then I'm gonna give you antibiotic=

8 MOM: [Right.

9 DOC: =ointment.

10 MOM: Okay:. Alright.

Each use of "Right" (lines 3/5) separately acknowledges the doctor's instructions. In this case the mother's acknowledgements are further positioned at points of possible completion (after "off," "that," and "Okay?"). Even though "scrape it off" is not brought to final-period intonation, the just prior "wi:pe it off." was. In addition, it is grammatically complete (Ford \& Thompson, 1996) and is replacing something that was also grammatically complete. ${ }^{3}$ Upon hearing a similar phrasing, this may further project to the mother that the doctor is coming to the completion of her turn. Each "Right." comes to final intonation which further displays each of the mother's acknowledgements to be complete lexical turn constructional units. Finally, the doctor orients to the different tokens as discrete units. For example, her "Okay?" targets the transition space following the first "Ri:ght." Similarly, her turn at line 6 is placed following the mother's "Right." in line 5. So, the doctor treats the mother's turn as complete in each location and thus shows her orientation to the tokens as discrete.

By contrast with this, the same word, phrase, or sentence can be said multiple times under a single intonation contour. For example, in the following extract, two colleagues, Bob and Tom, are discussing a problem and have taken up opposite positions. A teasing dispute has been in progress and continues across lines 1-2.

(2) Working group meeting TS 4/10/00

BOB: Ah- Ah- I deferred on thee earlier thing? on thuh

2 projection [( of thuh- )]

3 TOM: $\rightarrow \quad$ [Alright $>a^{\prime}$ ri]ght $=a^{\prime}$ right $=a^{\prime}$ right $=a^{\prime}$ right $<==$

OTH: $=(($ gene $[$ ral laughter $)) /(1.5)$

BOB: $\quad[(\wedge$ Ooh. $)$

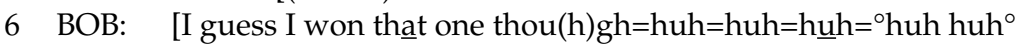


In contrast to the example in Extract 1, here the multiple saying of "Alright" in line 3 is delivered under a single intonation contour and as such does not reach possible intonational completion until the fifth repeat ("a'right<."). Repeats are not necessarily delivered very quickly (as they are here-noted with the compression markers " $><$ ") nor latched together (as noted with the equals signs " $="$ "), ${ }^{4}$ however, this is not uncommon in multiple sayings. Additionally, although each token of "Alright" comprises a syntactically complete unit, the turn constructional unit is treated as the full five repeats. The responses to the turn, both the general laughter (line 4) and Bob's acknowledgement (line 5), begin after the completion of the fifth token. The multiple saying in progress is thus treated as performing a single coherent action rather than as performing multiple discrete actions through multiple TCUs as in Example 1 above.

Next, a number of examples of different types of lexical, phrasal, and sentential multiples are offered in order to show the range of types of multiple sayings that occur in interaction, as well as what speakers may be doing in and through this practice.

\section{DATA AND METHOD}

The data for this article are drawn from a range of naturally occurring recorded interactions including ordinary telephone conversations, videotaped recordings of conversation over dinner and during cooking, and audio- and videotaped doctor-patient encounters. A majority of the data corpus are English language instances; however, as will be discussed, the practice has been found in Catalan, French, Hebrew, Japanese, Korean, Lao, Spanish, and Russian as well. The range of data support the argument that this practice is not restricted to a particular context of interaction (e.g., restricted to certain institutions or cultures), but rather occurs in a variety of communication contexts.

All English language examples were retranscribed by the author to verify whether or not prosodic boundaries existed between the items being repeated. Non-English language instances were returned to the native speakers who originally collected and transcribed the data and were asked to verify the accuracy of the transcription, paying particular attention to whether or not the repeated item was produced with final intonation after each item or not.

The data have been analyzed using conversation analysis (for a review see Heritage, 1984b). In line with this methodology, instances of the phenomenon were collected and similarities and differences among the collected instances were examined qualitatively. In this way the boundaries of the practice could be determined (see Schegloff, 1996 for a description 
of this process). The cases shown here are representative of the cases in the collection but were selected for two reasons: (a) to illustrate best the range of possibilities within multiple sayings (e.g., the types of items which are repeated; the contexts in which these objects occur), and (b) as particularly clear examples of the phenomenon, although they are not qualitatively different from other instances in the collection. This article relies on an auditory analysis of the prosody of multiples arguing that this shape appears to be systematic, recurrent and recognizable to interactants. ${ }^{5} \mathrm{~A}$ precise description of the acoustic properties of this practice would be an investigation in its own right.

\section{ANALYSIS}

Types of Multiple Sayings

Lexical Items

In these data, lexical items are the most common type of multiple sayings. We saw one example of this in Extract 2. Another example is shown below in Extract 3. This is taken from a phone call between a boyfriend and girlfriend who live some distance from one another and routinely exchange letters. Here, Hyla repeats the token "No" at line 3.

(3) Hyla and Rich

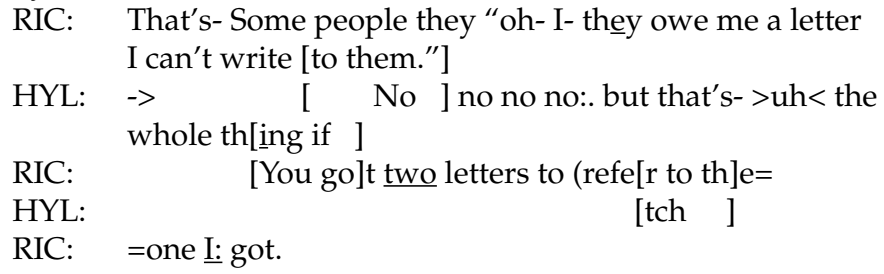

Similar to Extract 2, here the token is repeated multiple times before coming to period intonation, and the four-item multiple is delivered under a single intonation contour. In contrast to the example shown as Extract 2, there is evidence that the multiple saying need not be the only thing in the turn. That is, in Hyla's turn in lines 3-4, she not only produces the multiple of "No," but also continues her argument "but that's- $>$ uh $<$ the whole thing if". A third example is shown in Extract 4. Here, the extract is taken from a British medical encounter. The doctor is initially trying to secure the name of the patient he is about to see (line 1). The patient's mother offers the boy's last name "Sawy:er." Following still more delay (line 4), but despite the doctor having begun a "Ye:s.", the mother goes 
on to offer the boy's full name. In overlap the doctor repeats the token "Yes" (line 7).

(4) Pediatric Interaction LP 51

1 DOC: Now you're::

$2 \quad(0.2)$

MOM: Sawy:er.

$(0.3)$

DOC: Ye:[s. ]

MOM: [Ro]ber[t (Sawyer).]

DOC: $\rightarrow$ [Yes yes ye]s yes:: yes::

$(0.4)$

MOM: A very bad cough.=I had ta call the doctor ...

As with previous examples, here too the multiple saying is done under a single intonation contour although it consists of five tokens, each of which could stand on its own grammatically (as it did in line 5 here).

A final example is shown in Extract 5. Here, during a medical examination, the doctor is listening to the boy's chest with a stethoscope. At line 5 the doctor repeats the lexical item "Wait."

(5) Pediatric interaction 2081

1 DOC: Again,

2 BOY: .Hhhh hhhh.

DOC: Again,

BOY: .Hhhh hhhh.

DOC:-> Wait wait wait don't mo:ve, okay.=h=again,

BOY: .Hhhh hhhh.

7 DOC: Again,

Extract 5 additionally offers evidence that multiple sayings may be responsive not only to vocal behavior but to also nonvocal behavior (i.e., the child's having moved during the examination).

Extracts 2-5 are all examples of multiple lexical sayings. Versions of "yes" and "no" are the most common; however, other sorts of lexical items are also delivered as multiple sayings, including "Oh," "Okay," and "Good."

\section{Phrasal and Sentential Items}

More extensive units of talk are also done as multiple sayings. For example, in Extract 6 the phrase "Right there" is repeated. Here, as part of a 
pediatric visit, the doctor is verbally and physically examining a girl who fell from the monkey bars at school. As the doctor examines the girl's arm and requests clarification of where the girl hit her arm in the fall (lines 1-3), she is apparently pressing on the girl's arm. Just following confirmation by the girl with "Uh huh:," the girl comes in with the repeated phrase (line 5).

(6) Pediatric interaction 2028

1 DOC: Yeah:. so this is just where it lan[ded right here,

2 GIR: [.sshh

3 DOC: [Ri:ght?

4 GIR: [Uh huh:,

5 GIR:-> Right there=right there=right there.

6 GIR: .hh >B'see .h my- my uhm ...

Despite the phrase being slightly longer than the previous multiples shown, it too is delivered under a single intonation contour. The components are latched together and do not reach final intonation until after the third item in the multiple saying.

Multiple sayings comprised of sentences, while not nearly as common in the current data, do occur. Usually, like phrases, multiple sentential sayings tend to be short (i.e., two or three words). ${ }^{6}$ For example, see Extract 7 . Here, several friends are trying to persuade Vic to tell a story that he has told several times before. In line 10, Mike repeats the sentence "wait a minute" twice (as transcribed "Waidaminnit"). Again, the multiple saying is delivered under a single intonation contour coming to period intonation at the end of the second item.

(7) Upholstery shop p. 98 ((simplified))

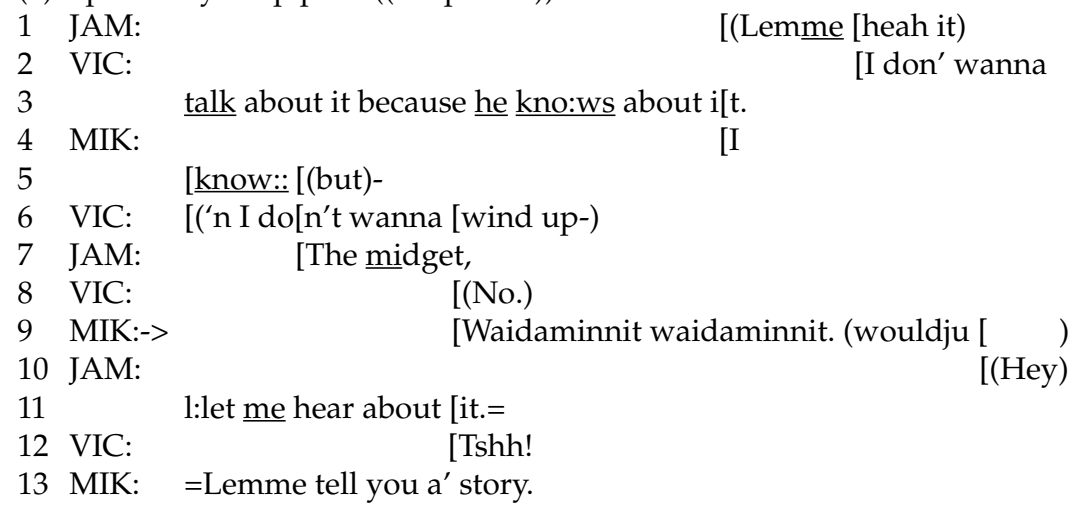


Finally, see Extract 8 for another sentential multiple. Here, three housemates have been preparing dinner and are presenting the fourth housemate, who has just arrived home, with what they are preparing. Robert repeats "I'll eat 'em" at lines 5-6.

(8) Housemate dinner 20:50

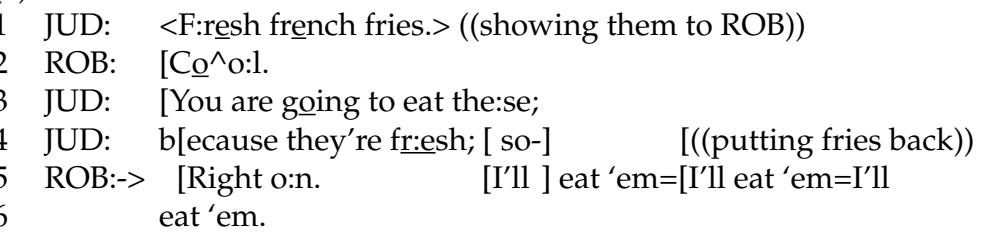

Here again, the multiple saying is done under a single intonation contour with a latching of each item to the next. Through his prosody, the speaker delivers this three item multiple as a single prosodic unit despite being composed of three syntactically complete sentences.

This section illustrated how multiple sayings may be comprised of lexical items, phrases, or sentences showing that, in all cases, the multiple is delivered under a single intonation contour across an entire turn constructional unit, regardless of the number of times the item is repeated. The cases shown here range from two to five repeats. ${ }^{7}$ Additionally, these instances offer evidence that the repeating performs an action that is analyzably discrete from the item being repeated. For an example, reexamine the case shown earlier as Extract 4.

(9) Pediatric interaction LP 51

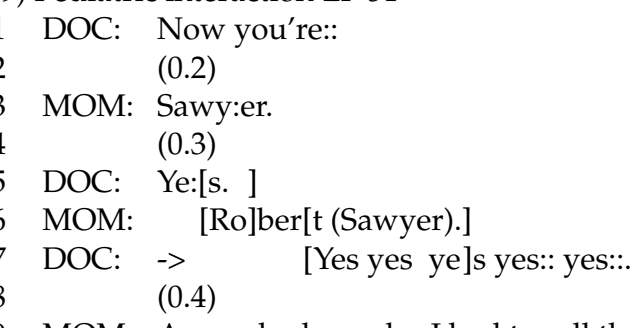

9 MOM: A very bad cough. $=$ I had ta call the doctor ...

The token "Yes" can be used, as it is at line 5, to acknowledge information. At line 7 the doctor's multiple saying performs an action that may, in fact, be at odds with the item being repeated. In contrast to what might be thought at first glance (as discussed by Müller, 1996) multiple sayings are not necessarily a more intense version of the same action performed 
by a single item. Specifically, although the token "Yes" is clearly important here insofar as its use as an acknowledgment token is at work, the multiple saying of it may in fact display to the mother that the provision of the full name was unnecessary and should properly be halted. Halting a course of action is at odds with acknowledgment, since acknowledgment furthers the in progress course of action. Additionally, the multiple saying of "yes" may further convey some measure of annoyance with the mother's persistence in offering her son's full name after the physician has claimed to know (line 5), a stance that is not conveyed by a single item "Yes."

This evidence that a range of different items may be repeated-and that, although what is repeated is clearly important for the interaction, the repeating is a communication practice in its own right and may be understood as analyzably separate from the item being repeated. The next section will examine the primary context in which these multiples occur, and begin to analyze their communicative function.

\section{Positioning and Function}

Generally multiple sayings, in contrast to a single item, target not only the turn to which they most proximately respond but also the larger course of action that that turn embodies. This function provides a solution to the interactional problem facing speakers whose turns are responsive not only to the immediately preceding unit of talk but to a larger course of action of which it is part. Existing research supports the assertion that most turns respond, and are understood as responsive, to the immediately preceding turn or TCU. This is so much the case that, for a turn to be understood as disjoined from its immediate sequential context, speakers recurrently mark it as disjoined with misplacement markers such as "By the way" (Schegloff \& Sacks, 1973). Further, this section will propose that multiple sayings are a resource that speakers have for displaying themselves to be dealing with an entire course of action and not only the just prior unit of talk. A "larger course of action" means an action that involves multiple "stages" or "steps" (Schegloff, 1995). Additionally, the function of multiple sayings is to display the speaker's stance against the prior speaker's perseverating course of action. In taking this stance through the production of a multiple saying, the speaker proposes that the course of action be halted.

As an example, see Extract 10. Here, John is calling Misty. Both are on cell phones. The stretch of talk shown here comes shortly after the beginning of the call. Misty asks John in line 1 where he is. After a repair initiation in line 3 , he responds in line 6 with a cut off "I'm drị:ving-". This is in overlap, and after another separate repair sequence (lines 7-9), he redoes 
his response with "I am drị:ving" (line10) and then substantially expands his response across lines 10-25. At line 26 Misty does a multiple of "Okay".

(10) Cellphone call

1 MIS: Where are you?

$(0.3)$

JOH: Where a $\mathrm{am}$ I?

MIS: yuh.

(1.0)

JOH: [I'm drị:ving- ]

MIS: [I'm just curiou]s

JOH: Huh?

MIS: I'm j(h)ust cu (h)rio(h)us.

$10 \mathrm{JOH}: \quad$ I am drị:ving up something ca:lled (0.9)

11 Post Joanne Roa:d.

12 MIS: ((crunch)) mmhm ((crunching))

$13 \mathrm{JOH}:$ If you loo:k behind me about-

14 eight miles you come to: (.) Post Joanne.

$15 \quad(1.5)$

$16 \mathrm{JOH}: \quad$ where the ferry leaves for Blaa:nk Island.

$17 \quad$ (.) ((crunching))

18 MIS: Oh-.

$19 \quad$ (1.3) ((crunching))

$20 \mathrm{JOH}$ : If you look ahea:d,hh you come to an entrance ra:mp

21 tọ: a sort of limited access highway? Route Nị:ne.

$22 \quad(1.0)$ ((crunching throughout))

23 MIS: ((swallow)) Uh huh

$24 \mathrm{JOH}$ : which is gonna ta:ke me North towards: The Beaufort

26 MIS: = [okay okay] okay. In the car was reallyhh

27 MIS: [( ) ]

$28 \mathrm{JOH}: \quad$ I'm in the car. hh heh heh heh hah hah hah [.hh Sorry hh

29

[((crunching)) [((crunch))

The multiple saying of "okay" here targets not only the just prior component of talk, but rather the entire course of action, the detailing of exactly where he is that is provided from lines 10-25. John's response to Misty's question "Where are you?" was adequately answered with his indication that he was driving (as she later indicates at line 26). What John provides following the two repair sequences, however, is a very detailed account of where he is: the road he is on; what is behind him; what is ahead of him; and finally what he cannot see yet but what is ahead of him in the more distal sense: "Route Nị:ne. which is gonna ta:ke me North towards: The Beaufort ..." 
Across this extended detailing Misty offers the acknowledgment "Oh" in line 18 and a continuer in line 23 with other silences following points of possible completion. Her multiple saying of "Okay" is positioned midTCU of John's description of where he is as it gets most distal. As mentioned earlier, the course of action in which John is engaged is describing where he is in detail. It is not simply a single TCU answer to her question. Additionally, this course of action was clearly not what Misty had requested, and this is oriented to as overdone by Misty with the multiple, the next TCU and her laughter in line 26, and by John (line 28) with his laughter and his apology. The perseveration of this course of action is in the granularity with which he details "where" he is. Misty's multiple saying of "Okay," protests this perseveration. Further evidence for this is seen in the TCU following Misty's multiple at line 26 where she specifies "In the car was really" where the likely completion was "enough."

A final point here is that it is quite common for multiple sayings to be positioned in overlap with the just prior TCU. By beginning in overlap, the speaker of the multiple saying may be doing additional work to display his/her understanding of the ongoing talk as part of an unwarranted and persistent course of action. In this case, it is John's fourth round of information about his location that is overlapped, and in overlapping this with a multiple saying, Misty displays her stance that this trajectory of talk should properly halt and that further talk is unwarranted. ${ }^{8}$

A similar case is shown in Extract (11). Here, a number of colleagues are taking part in a working group meeting. Tom has just articulated his position on the current problem. Across this extract Bob and Tom take opposing positions in a couple of different ways. First, Tom is treating Bob's behavior as problematic. He treats Bob as taking a position counter to Tom's in order to create conflict and then "winning" the conflict. In addition, however, Tom is maintaining a joking or teasing frame while Bob is taking up each of Tom's turns as serious. Tom's multiple saying comes at a point where Bob is again supporting his opinion that their recurrent opposition is unproblematic, but simultaneously treating the accusation as a serious one. Both dimensions of this are relevant here.

(11) Working group meeting ((W1 and W2 are specific individuals;

OTH are unidentified others in the group))

1 BOB: Really.

2 BOB: I [hear it as just thee oppos [ite.

3 TOM: [Yeah. [ $€$ Uh huh,$£$

4 BOB: .h I hea[rd i-

5 TOM: [Not thuh first time you've gone (for [that)

6 BOB: [Ah- 


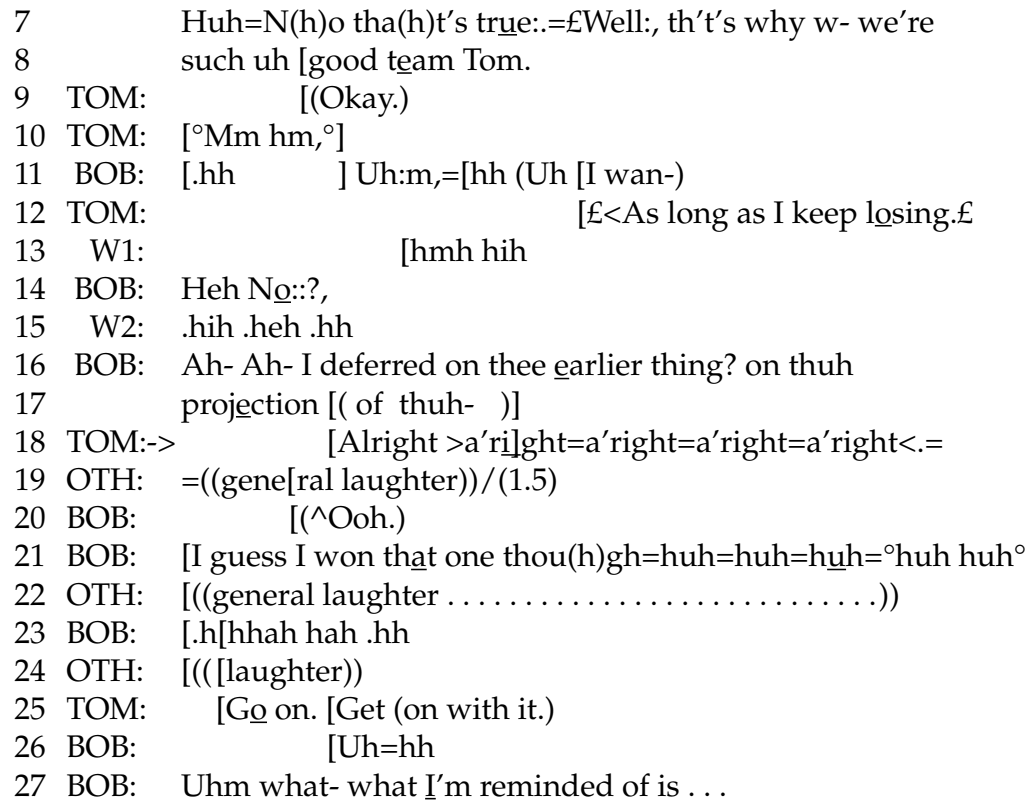

In line 2, Bob responds to Tom's opinion indicating that his position on the point they are discussing is contrary. In overlap with Bob's explication of this position in line 4, Tom offers an accusation "Not thuh first time you've gone (for that)". Both the continuer (line 3) and the accusation (line 5) treat Bob's announcement as "not news". Both treat the announcement of a contrary opinion as a repeat occurrence (and offense). In addition, the smile voice in line 3 across the continuer displays Tom's orientation to Bob's announcement (or perhaps the repeated occurrence of it) as humorous. In line 7, Bob acknowledges and confirms Tom's accusation in line 5 but then characterizes their recurrent disagreements as a positive feature of their relationship, that is the reason they are "such uh good team" (line 8). There are laugh tokens in Bob's admission and subsequent smile voice; however, the turn nonetheless treats Tom's accusation as serious. In addition, Bob not only responds to Tom, but also addresses the underlying assumption of Tom's turn, that these recurrent conflicts are a problem.

Tom has indicated acquiesence with his early "Okay." (line 9) and then his minimally agreeing " ${ }^{\circ} \mathrm{Mm} \mathrm{hm},{ }^{\circ}$, " (line 10); however, as Bob moves to resume an articulation of his position (line 11), Tom offers an increment to Bob's previous turn (lines 7-8) (Schegloff, 2000). This increment (line 12), by virtue of being designed to add to a turn that was sequence closing, is designed to be sequence final. It is simultaneously an accusation, a second accusation to the one offered at line 5. This accusation is then an 
upgrade on the previous thereby pressing further for a response. There are thus cross-cutting relevancies surrounding Tom's increment: It is both sequence closing and sequence initiating. As an increment to what was designedly sequence closing, the turn appears to be produced as a quip, a "last word" on the topic. In this environment, however, Bob takes it up as a sequence initial accusation and first denies it (line 14) and then refutes it (line 16).

Following his refutation, Bob explicates the reference in line 17. Tom's turns across this extract appear to be designed both to pursue his position that Bob and Tom's opposition is problematic, but also to tease (searching for laughter). Bob does not wholly take up the teasing dimension of Tom's turns but does take up the serious dimension of each one. As a result, when Tom produces a multiple saying in line 18 , he is potentially dealing both with having "failed" to argue that the opposition is problematic and to accomplish teasing. Both elements are present in Bob's increment at lines 16-17 which acts as an instantiation of the larger course of action Bob has been engaged in and to which Tom's multiple saying is responding.

The multiple saying of "Alright" here acknowledges the prior talk and proposes closure of the sequence. This is regularly accomplished with a single token of "Alright" (Beach, 1995; Schegloff, 1995). With the multiple saying of "Alright," Tom works to display that his turn is targeting the larger course of action, not simply the just prior unit of talk. Tom further conveys that Bob's course of action has persisted beyond what was warranted and thus should properly halt. Tom treats Bob's increment (the unit of talk that he is most locally responding to) as an instantiation of a larger course of action that is being addressed with the multiple saying, and it is this course of action that the multiple saying is designed to halt, not simply the in-progress TCU. Indeed that is what happens. Similar to John in Extract 10, Bob halts his course of action mid-turn and does not re-initiate it once in the clear of overlapping with Tom. Rather, both Bob and the rest of the group hear Tom to be "folding" with his repeat of "Alright" (line 18). This is evidenced both by the general laughter that immediately follows the repeat (line 19), and further, and more explicitly, by Bob's "I guess I won that one thou(h)gh=huh=huh=huhh= ${ }^{\circ}$ huh huh" (line 21). Finally, following this, they move back to work (initiated at line 25 and begun at line 27).

Bob's treatment of Tom's increment in lines 7-8 as a first positioned accusation was a relevant next action; however, as a response to a designedly sequence closing quip, it pursues this discussion unnecessarily. In this extract, Tom treats Bob's course of action as persisting in a conflict when the continuation was unwarranted. Bob had repeatedly resisted Tom's teasing frame and had responded instead to each of Tom's accusations as serious. In addition, Bob's refutations led to an opposing position 
in and of itself (i.e., that recurrent opposing positions are not problematic). Bob has previously taken this position, and just prior to the multiple saying, he is once again making this position relevant. Tom's multiple saying thus treats this reinvocation as unwarranted and thus as problematic and proposes that Bob halt his course of action.

A third example is shown in Extract 12. Just prior to this extract, Judy had been talking to two of her three housemates about the meal they are preparing. Among the housemates there was speculation about whether or not Robert, the fourth housemate who was not yet home, would be willing to eat the meal they were preparing. He is generally against eating either junk food or animal products, and their meal (french fries and chili burgers) was potentially guilty on both counts. The dish that Robert was most likely to eat, however, was the french fries, because they were home-made and therefore perhaps less like junk food. When Robert comes home, after a brief description of his shopping experience, Judy presents him with the french fries.

At line 1, Judy emphatically announces (as seen through the stretch and emphasis on "F:resh" and the slow tempo of the entire phrase) the least offensive food (french fries) highlighting the aspect of these fries which makes them the least "junky."

(12) Housemate dinner

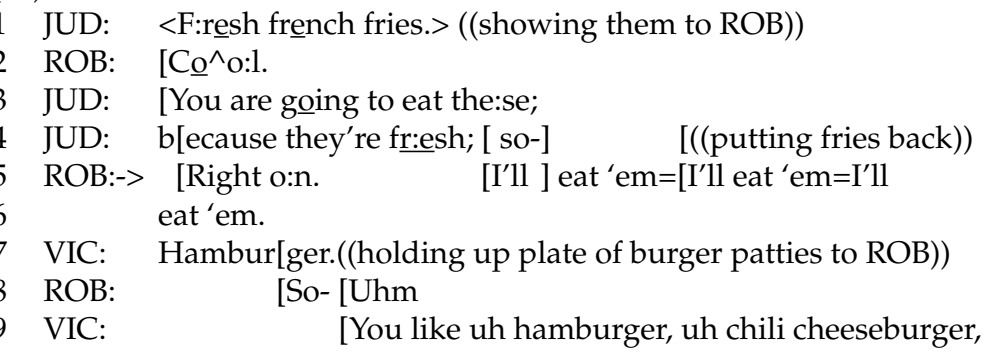

Immediately following the announcement, Judy issues a directive (line 3). This directive is done quite strongly, including holding the french fries up for Robert's visual inspection. Robert offers a very positive assessment "Right o:n." (line 5) in response. This response, however, was slightly late, and Judy had quickly pursued his agreement, providing little more than a transition space of time and following rather equivocal intonation. The pursuit here involves providing him with a rationale that preemptively addresses his most likely reason for not agreeing to eat the fries. This pursuit ends up being in overlap with his response to line 3 ("Right o:n.") but even upon hearing "Right o:n," it is not abandoned. This very positive assessment is in fact Robert's second (the first being at line 2) 
indication of his likely willingness to eat the fries. In this environment, Judy pursues explicit agreement with "because they're fr:esh;". In response, Robert offers a repeated "I'll eat 'em" in lines 5-6.

The multiple saying is positioned not simply by reference to line 4 but by reference to line 4 as a pursuit of her previous imperative "You are going to eat the:se;". The course of action Judy is involved in here is securing agreement from Robert that he will eat the french fries. The first attempt at this was made in line 1 with the announcement. Note that this is not simply an announcement of french fries but of "fr:esh;" french fries. The emphasis on "fr:esh;" is noteworthy in part because it treats that feature of them as criterial to Robert's agreement, and additionally, it provides a resource for Judy to tie back to in line 4 . Thus, line 4 is delivered specifically as part of an extended course of action begun at line 1 .

Once articulated by Judy in line 4, the reuse of the term "fresh" becomes a resource for Robert's understanding of the turn as a pursuit. In particular, the two sequences (lines 1-2 and lines 3-5) come so close together that there is no need to explicate the connection between Judy's line 1 and line 3. As a result, when she does explicitly tie the two sequences together with the account in line 4 , she is heard pursuing a course of action beyond what is warranted. By doing a multiple saying of "I'll eat 'em", Robert communicates that he understands the trajectory of Judy's talk; that her persistence is unwarranted; and finally, that she should properly halt her course of action. Again, what appears problematic is that Robert has twice indicated a favorable orientation towards the french fries (lines 2 and 5); however, Judy nonetheless persists in an effort to secure explicit agreement to eat the fries. The perseveration here is most obvious in her reuse of "fr:esh;" which appears to be a resource for insisting that Robert do something that he has already displayed willingness to do.

Judy not only abandons her turn in response to the beginning of the multiple, but perhaps more importantly, as soon as it is clear that Robert is on a trajectory of repeating "I'll eat 'em," Judy turns away (line 4), thus displaying a similar "folding" to that seen in Extract 11. Judy here nonvocally "folds" in that she displays herself to have abandoned her previous course of action. She also does this before the multiple saying is complete, which provides evidence that it was hearable as a multiple saying early in its production. At the close of that sequence, Victor initiates a similar sequence this time bringing the raw hamburger patties to Robert and suggesting that he eat them. In partial overlap, Robert (line 8) initiates a move to resume what is likely his just prior telling about his shopping adventure (indeed this is successfully resumed by Robert with "So" just slightly later: data not shown). Judy, Robert, and Victor thus all display orientations to Robert's multiple saying as having communicated that that course of action could and should be halted, and Judy complies with this. 
The previous three examples all show the speaker of the multiple as "folding" or "giving in" to the other person. In this way, speakers display both that the prior speaker's course of action was overdone and that it should properly stop. Another way in which perseveration can be problematic is when it reveals a problem with the content of the talk. For example, in the following exchange, Hyla and Rich, as noted earlier, are dating. Hyla is concerned with figuring out the sequencing of their letter exchange because she has received an "early" letter from Rich. Rich adopts a stance in which he attributes to Hyla a position that he sees as "crazy" involving rules of letter writing. Through his course of action, Rich conveys that he finds such rules problematic, and through his attribution of this position to Hyla, he conveys a problem with Hyla. Hyla's multiple saying of "No" in line 22 rejects his course of action.

\section{(13) Hyla and Rich}

HYL: Did mine come on the sixth, cuz that's when it shoul [da ] come.=

RIC: $\quad[\mathrm{hh}]$

RIC: =No I- I think yours came before that.

RIC: I don't- yuh know I don't stamp my letters when they come in. write dow[n the day or [nothing.

HYL: [uh- [.hmfhh

HYL: .h alri- no the only reason I'm say:ing is because I mailed it on Monday figuring you'd get it on Wednesday: .h an' then (.) I got a letter ^ $\underline{\text { Friday from }}$ yoü:: (.)

RIC: Oh I- I wrote=you a letter before you wrote me a letter(h).

RIC: -> I don't believe any uh that horseshit you gotta owe

1-> some[one a letter:-

HYL: [uh-

17 HYL: $-\mathrm{h}[\mathrm{h}$

18 RIC:2-> [That's crazy.

19 HYL: Wha(h) What?

20 RIC:3-> That's- Some people they "oh- I- they owe me a letter

I can't write [to them."]

HYL:-> [ No ] no no no:. but that's- > uh< the

4 RIC: [You go]t two letters to (refe[r to th] $=$

HYL: [tch ]

26 RIC: =one I: got.)

27 HYL: Wha::?

28 RIC: Ye- you got another letter coming.=You shoulda gotten two 
Lines 12-13 ("Oh I-I wrote-you a letter before you wrote me a letter(h)") not only respond to Hyla by offering a possible solution to the puzzle she had been formulating in terms of letter sequencing, but also implicitly suggests Rich's orientation to letter writing as not needing to have rules of reciprocity. This position was not acknowledged by Hyla, and Rich then takes a more explicit position (lines 14-15) regarding letter sequencing "I don't believe any uh that horseshit you gotta owe someone a letter:_". By rejecting this position, he treats Hyla as having taken up such a position. In this way, this turn begins a course of action pursuing at least acknowledgement from Hyla regarding their difference of opinion. Hyla appears to begin to respond in line 16 with "uh", but this is abandoned, and then there is a slight laugh in line 17.

Rich upgrades his position with his assessment "That's crazy". This assesses the position that by now is hearably being attributed to Hyla: that people shouldn't write letters until they have received a letter. In response to this assessment, Hyla laughingly initiates repair on Rich's turn (line 19). According to Drew, open class repair initiators such as "What?" commonly occur in contexts where the speaker is having trouble, not so much with what was said, but why it was said (1997). He suggests that these repair initiators orient to a problematic sequential relationship between the repairable turn and its sequential context. In this case, the puzzle for Hyla is how Rich arrived at the perspective that she held the view that he is now calling "crazy." Rich initially begins a response that treats Hyla's repair initiation as a trouble of hearing (with his redoing of "That's-"); however, this is then abandoned and his repair next treats the problem as one of understanding. Specifically, his repair offers an explicit characterization of the opposing position-thus not backing down but maintaining his stance. This is accomplished with the mock reported speech of someone who felt that letter writing requires appropriate turn taking. Rich's TCU then can be understood as an embodiment of the larger course of action in which he has been engaged: pursuing acknowledgment of his rather negative characterization of Hyla's position that writing must adhere to rigid turn taking rules. In response to this characterization, Hyla does a multiple saying with the item "No."

Understanding the positioning of this multiple saying is critical to understanding it as working to halt an in-progress course of action. In this case, Hyla is treated by Rich as having taken a position that she is too rule-based. She does not align with this as her position; however, he nonetheless pursues this further. Subsequently she initiates repair indicating disaffiliation (Drew, 1997), but he pursues still further, thus protracting the course of action in which he was engaged. It is in this sense that he persists in a course of action beyond what was warranted. In contrast to the cases examined thus far, here it is not simply the perseveration of the 
course of action that is problematic but rather what this perseveration has revealed.

A final example is shown in Extract 14. Here, the multiple initiates third position repair. Schegloff (1992) noted that multiple "no"s can initiate third position repair; however, the most common initiation appears to be a single "No" and a "rejection component" such as "I don't mean X" (Schegloff, 1992). What is further accomplished with the initation of repair with a multiple is, like the other instances we have observed, that the multiple targets a larger course of action as problematic. In Extract 14, Mark's multiple saying of "No" in line 37, is placed, most locally, by reference to Kim's question "You might lose hęr?" (line 36). Kim's question, however, serves as an instantiation of a failed understanding that has apparently developed across the larger sequence.

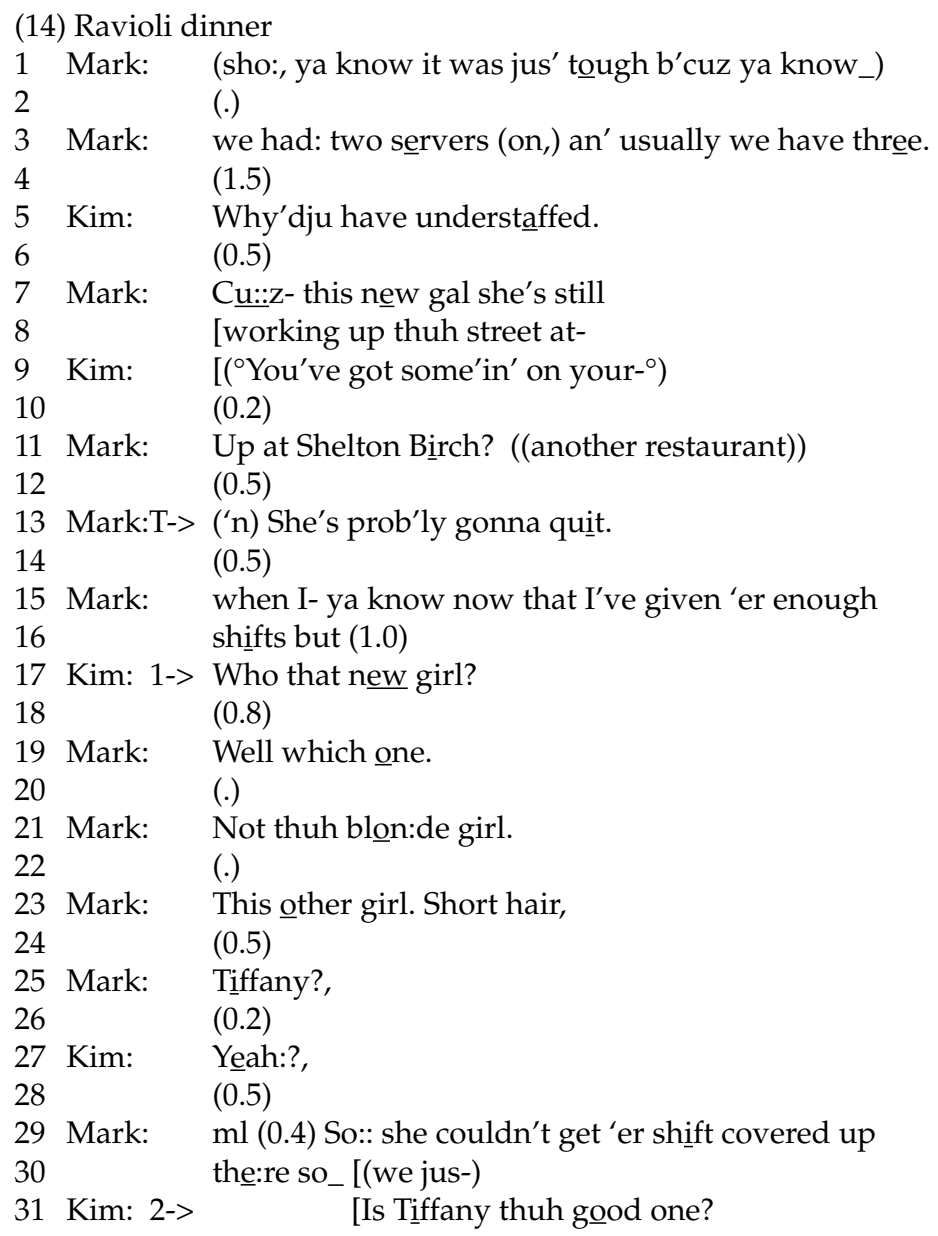




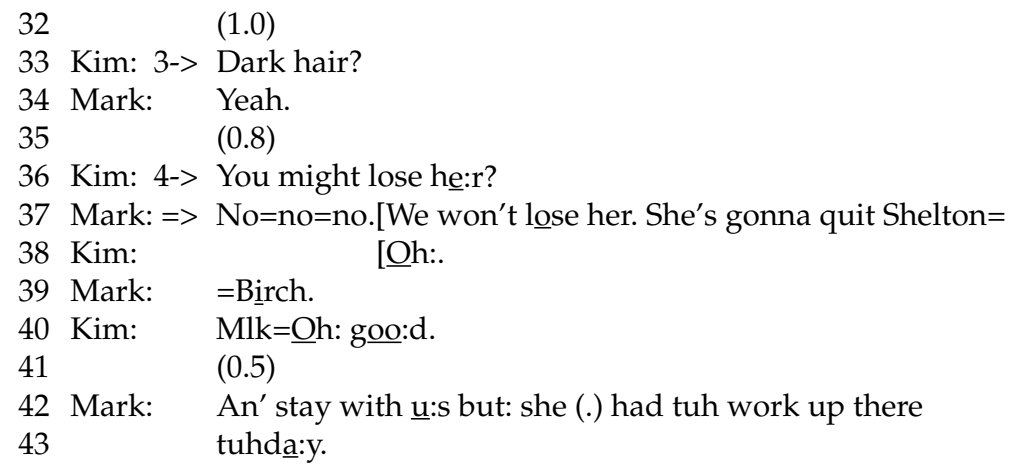

Just prior to this extract, Mark had been telling Kim about his day. At line 5, Kim initiates a new sequence. Mark's turn across lines 7-16 is concerned with answering her question. Looking ahead to the location of the multiple saying in line 37, the TCU it is locally responding to is one in which Kim, with the stress on "he:r," reflects her understanding that what was critical about Mark's response to her question in line 5 about why his restaurant was understaffed was that one of the servers was going to quit (the trouble source). The ambiguity that develops appears to revolve around whether the server would be quitting Mark's restaurant or whether she was quitting another job. Kim treats the import of Mark's turn to be that the "new gal" is going to quit Mark's restaurant. She then pursues securing the identity of this person in order to better assess what sort of impact this will have on Mark (i.e., whether he would be losing a good server or a mediocre one) with multiple questions.

As seen at the end of this sequence, the identity of the server who was not working is only relevant because the account for her absence is that having just started working at the restaurant, she has not completed all of her other previous job commitments. The conflict between her working for Mark and her working elsewhere thus will not exist for much longer. Mark was likely offering this account by way of noting that the problem of them being understaffed was a temporary one.

As the sequence unfolds, Kim's questions at line 17, 31, and 33, and Mark's responses and explications in lines 19, 21, 23, 25, and 34, all work to secure the identity of the "new gal" referred to by Mark in line 7. Each is working toward further clarification. This securing of the girl's identity is used to inform Kim's response to Mark's telling in line 36 with the request for confirmation "You might lose he:r?" At the same time, this question belies that the sequence initiated by Kim with "Who that new girl?" was part of a larger course of action designed to determine the new girl's identity before taking up the news that she was quitting. As an instantiation of this larger course of action, Kim's turn at line 36 belies her 
misunderstanding of Mark's telling, something Mark addresses following his repeat in line 37.

Here, what is at issue is that Kim is pursuing a course of action, securing the identity of the server in question, that is not appropriate. The inappropriateness is because this course of action was in the service of producing an appropriate response to Mark's announcement that the girl was quitting: either positive (losing someone that he now does not have to fire) or negative (losing someone he will need to replace). As the server was not quitting Mark's restaurant at all but rather was quitting a different restaurant (see lines 37-38), an understanding of this is unnecessary. The multiple saying of "No" here is designed to show that not only is the question "You might lose he:r?" (line 36) inappropriate, but the entire preceding course of action was unwarranted and should not be pursued further.

This is a case of third position repair where the trouble source is Mark's mention (at "T->") of the girl quitting. Kim's request for clarification of whether the girl is quitting reflects a problematic understanding of Mark's earlier turn. When Mark initiates repair on Kim's utterance, he is in a position of working to display that his rejection of Kim's question is not simply a "No she is not quitting" answer to her question, but is a rejection of the question entirely, a rejection of its appropriateness and relevance as a question. The multiple saying of "no" here addresses this interactional dilemma.

In this section, multiple sayings were shown to be positioned by reference to TCUs that act as instantiations of larger courses of action. Multiple sayings can then be seen to address that larger course of action. Multiple sayings provide a resource for interactants to display that their turn is addressing not only the just prior unit of talk, but rather the larger preceding course of action. Beyond this, multiple sayings work to convey that the speaker has found the prior speaker's course of action to have perseverated needlessly and proposes that the course of action be halted.

\section{Multiple Sayings in Other Languages}

Multiple sayings are not restricted to English. Even though I have not systematically investigated data in other languages, instances have been observed in Catalan, French, Hebrew, Japanese, Korean, Lao, Russian, and Spanish. They appear to work in the same basic way. For example, the following instance is taken from Japanese data. Here, a multiple saying displays Kyoko's orientation to Asami's course of action.

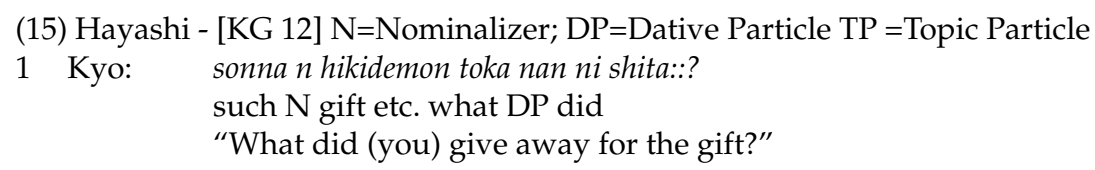


2 Asa: atashi wa are:: (.) HAchi mitaina.

I TP that bowl like

"I (gave) THA::T (.) like a bowl."

3

(0.7)/((Asami makes iconic gesture of a bowl))

4 Asa:

$\begin{array}{ccc}((\text { sniff })) \text { hitotsu no:: } & \text { [(oboteru? } & \text { [chikachan.) } \\ \text { one. piece's } & \text { remember } & \text { Chika } \\ \text { "((sniff)) one piece of:: } & \text { [Do you remember [Chika?" }\end{array}$

5 Kyo: ->

$\begin{array}{lll}\rightarrow & {[a \cdots::} & h a::: \\ & \mathrm{Oh} & \text { I see } \\ & \text { “Oh } & \text { I see }\end{array}$

[ha::: ha::: ha:::

I see I see I see

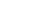

6 Chika:->

[un .

Yeah

$->$

["Yeah

In this example, three friends are talking. Asami is pursuing a course of action involving trying to get Kyoko and Chika to recognize a gift that she recently gave someone (lines 2-3) as a response to Kyoko's question (line 1). At first possible completion after "are::" or "THA::T," Kyko does not display recognition, nor does Chika, who actually attended the wedding. Following her second effort, which reaches possible completion after "mitaina." or "bowl.", still neither woman displays recognition. At this point Asami makes an iconic gesture of a bowl. Still, neither woman responds. A fourth effort is begun in line 4, as Asami begins another description with "hitotsu no::" or "one piece of::". To achieve recognition of a simple item (a bowl) has taken substantial effort by Asami, especially in a context where one participant (Chika) should know what the gift was. Asami's effort in line 4 to overtly enlist Chika's help may be responsive to this protraction. It is in this position, in overlap with "oboeteru?" (line 3), that Kyoko offers a change-of-state token " $a$ :::" or "Oh" (Heritage, 1984a), and then a repeated "ha:::" or "I see." The "a:::" claims recognition of the type of bowl that Asami has been working to describe. This multiple saying, similar to others we have examined in English, claims that further description is unnecessary. Here it may be not only that the sequence has become protracted, but also that Kyoko is oriented to her own lack of recognition of this simple item. The multiple proposes and achieves sequence closure similar to the English examples shown earlier.

Another example, shown below, is taken from a phone call between two Russian friends discussing a car accident in which someone badly hurt his arm. At line 90, Vova reveals that he had misunderstood from Oleg's telling that their friend had been driving when he was in the accident. In response (line 91) Oleg offers a multiple saying of "Net" or "No" 
as an initiation of third position repair similar to Extract 14. In Extract 16, the source of the misunderstanding was substantially before the TCU in line 90 that Oleg's multiple saying is locally responsive to.

(16) Bolden RP call 2; PRT=Particle

1 OLEG: [Nu takk vsë bolee nimenee nichevo:/

PRT PRT all more less nothing

So everything is more or less good.

2

tok[a etat/ (.) papa:l/ (.) v avariju/

only PRT got in accident

Only that one got into accident

((12 lines not shown-clarification of who was in the accident and that there was an accident))

14 OLEG: Znachit eh:on eh zimo:j mashinu razvernu,la/

means he wintercar turned

So he eh in the winter the car got turned

15 VOVA: Uh-mh

16 OLEG: Eh::: $i$ udarila ab etat ab agrazhde:nie/ and crashed at PRT at railing and crashed into a railing

17

(.)

18 VOVA: Ah-hah

19

20 OLEG: Eh: I: emu::eh razdrabila (.) p-pravuju ru:ku/ and him smashed right arm and his right armed got smashed/broken to pieces

((60 lines not shown—about his injury, hospitalization, and mental state))

81 OLEG: $\quad N^{\wedge} u$ shto sdelaesh/Vobschem vot $v$ takom vot duxe/= PRT what you-do in-general PRT in su_PRT spirit What can you do/ So this is what things are like

82 VOVA: =A:: panjatna/.hh Dạ:/ $<$ A vsë astal'noe narmal'na/= understood yes PRT all rest nomral Oh I see/ Yes/ Everything else is fine 
84 OLEG: Da:/ Tak bolee 'menie vsë [Ønarmal'na/= yes so more less all normal Yes more or less everything is fine

85 VOVA:

[eh

86 VOVA: $=[\mathrm{uhm}$

87 OLEG: =[N'v't pomjal svoj dzhi:p etot samyj/

PRT bended self jeep that very

He put a bend on his jeep

88 VOVA: D $\underline{a}, /=u$ nevo $d z h \underline{i}, p$ byl/ dal

yes with him jeep was yes

Yes he had a jeep right

89 OLEG: U nevo Taë:ta/<Da xaro:shij dzhi:p takoj/= with him Toyota yes good jeep such He has Toyota Yes a good jeep

90 VOVA: $\quad=\underline{A}-<A$ : on sa ? $m$ byl za rulë, $m / d a /$

oh PRT he himself was at wheel right

$\mathrm{Oh} / \mathrm{He}$ was the one driving right

91 OLEG:-> Net net net/

no no no

92 VOVA: $\underline{A}: /$

93 OLEG: On s-[sidel spra:,va]=

he sat right

He was sitting on the right

94 VOVA: [kh-kh

95 OLEG: =a vaditel' (.) za rulëm byl and driver at wheel was and a driver was at the wheel

96 VOVA: A::: 
At line 2 Oleg announces to Vova that someone had been in a car accident. The turn does not state who. It is also ambiguous in its formulation (both in Russian and in the English translation) as to whether or not the person in the accident was driving. By the same token, as in English, native Russian speakers assert that the formulation "popa:l (.) v avariju" or "got into accident" has a default understanding that the person was likely driving. This turn at talk becomes the trouble source later in the conversation.

After a stretch of talk involved with specifying the accident (shown in lines 14-20) and then a stretch of talk not shown about the man's injuries, his hospitalization, and how he is managing, Oleg (line 81) offers two aphoristic statements "What can you do." and "So this is what things are like." Both orient to the larger telling sequence as complete (Schegloff, 1995). In this environment, however, Vova receipts the larger telling as news and then offers a summation of it for confirmation (lines 82-83). Oleg confirms this in line 84 .

In line 87, Oleg offers a bit more information about the accident. Similar to line 2, this TCU is somewhat equivocal as far as whether the man was driving. There are, however, two ways in which this understanding is unproblematic. First, the agent of the sentence appears to have been male: Even though the sentence has a zero subject, it can be understood to be masculine through the verb "pomjal" which implies masculine gender. Second, the car involved is noted as belonging to him (with "svoj" or "his"). When Vova, at line 90, requests confirmation that the friend was in fact driving, he has had multiple places from which to derive this understanding. Important here is that the multiple saying is in the environment where a substantial amount of talk is predicated, for Oleg, on the idea that their friend was a passenger. In fact, just 6 lines earlier the topic was being closed. When Vova reveals this misunderstanding, it draws into question a very substantial course of action that may have been misunderstood. The multiple saying, similar to others we have seen in English, thus works to address that and shows that it is not simply the TCU requesting confirmation that is being disconfirmed, but the larger course of action. Similar to other cases, the speaker here conveys that the course of action that had been in progress should properly halt, here, similar to Extract 14, because there is a flawed understanding of the events.

This section has offered examples from two languages that are quite different from English, and from each other, as evidence that the practice of multiple sayings is not restricted to English, but is a rather more pervasive communication practice. As has been seen across both English and non-English examples, multiple sayings (no matter what the basic item) treat the just prior unit of talk as embodying a larger course of action. In that way, multiple sayings address that course of action in order to assert 
that the course of action has become problematic and need not continue and should properly be halted.

Speaker Orientations to the Significance of Multiple Sayings

A final piece of evidence in support of the argument developed here is found in the way that speakers can, in the course of a turn, work to move from a turn that either projected or failed to project a multiple saying into an alternative form. For example, in Extract 17, a speaker begins and then abandons a multiple saying. Here Judy is asking her housemate Robert about an ice pack. Robert has several icepacks that are stored in the freezer. At some point in the past, Robert saw Judy putting an ice pack in the freezer and assumed that it was hers. In fact, as is stated in this extract, that ice pack was Robert's. The ownership of that ice pack is relevant to our understanding of this extract. In line 1, Judy asks Robert if he has an ice pack. At line 8, Robert displays his understanding that Judy is asking about an ice pack that belongs to her. This, however, is disputed by Judy (line 10), who asserts that the ice packs that were in the freezer previously had, in fact, been Robert's. In reponse to "No those're your:s," Robert begins a repeated "No" (line 13).

(17) Housemates (34:00)

1 JUD: Rob do you have (0.5) an ice pack, (\#hm\#)

2 ROB: ( ) ((to BRU))

JUD: that you took outta thuh fre[e-

ROB: $\quad[y=I:-y-y-y-y-$ If- you [fou:nd those,

BR?: [Oahgh

6 JUD: $\quad\left[\mathrm{N}^{\wedge} \mathrm{O}:\right.$. you took 'em outta thuh [freezer.

BR?: $[(\quad)$

ROB: [I- I've lost mị:ne tooo:.

9 ROB: (I'm about $\mathrm{t}\left[\mathrm{o} \mathrm{I}^{\prime} \mathrm{ll}-\right)$

10 JUD: [No those're your:s.

$11 \quad(0.2)$

12 JUD: [(that I put] in the freezer.)

13 ROB:-> [No n' n- ]

$14 \quad(0.5)$

15 ROB: Blue ones?

16 (.)

17 ROB: were mine too?

$18 \quad(0.4) /(($ swallow; slight nod by Judy $))$

19 JUD: And thuh white one?,

20 ROB: Thuh white one (I) was mine. 
Robert's multiple saying of "no" initially appears to be addressing Judy's assumption that the ice packs she has been referring to belong to Robert not her. It treats Judy as wrongly persisting in a course of action. That is, her first question (line 1) is treated as indicating that she has lost her ice pack rather than as a pre-request to borrow one of his ice packs. In overlap with the multiple saying, however, Judy adds an increment "(that I put in the freezer.)" (line 12). The increment offers further evidence for Judy's claim that the ice packs were in fact Robert's and not hers, even though she put them in the freezer. Upon hearing "that I put," Robert abandons his multiple saying. In doing so, he withdraws his attempt to close down Judy's prior course of action and instead further pursues clarification in lines 15 and 17.

A second example provides similar evidence for the use of multiple sayings, but instead of a projected multiple saying that is abandoned, here we see a projected single token that is subsequently transformed into a multiple saying. The speaker displays an understanding of the multiple saying as a practice for accomplishing something different from the single token. In this case, Marion and Tom are students in the same class at school. Marion has called Tom and at this point in the call Tom asks about the class they share (lines 1-2, 4). In response to Tom's pursuit of this information (lines 8-9), Marion begins to detail the information about their upcoming exam (lines 10-16).

(18) North Hills

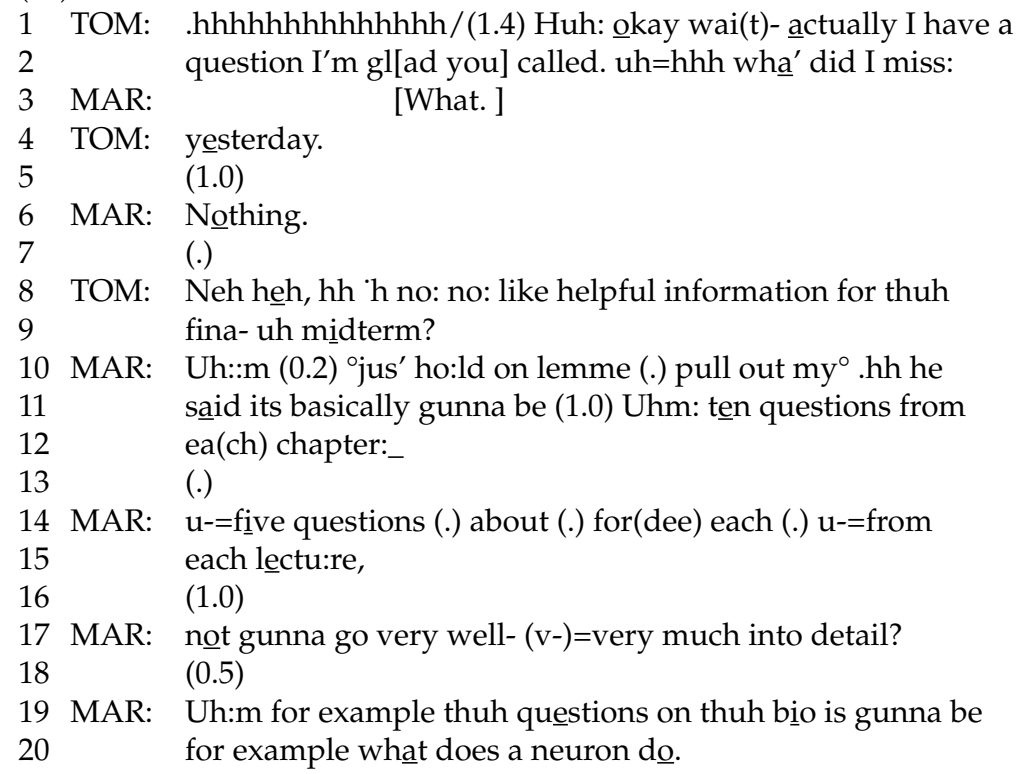




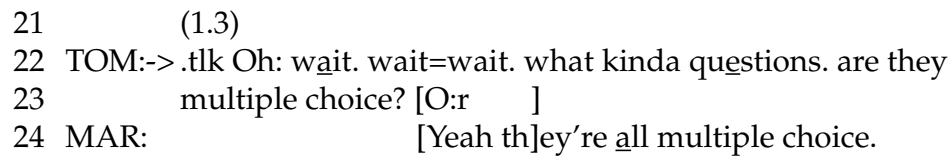

During her turn, Marion offers a cursory summary of her notes as projected in line 10 with "lemme (.) pull out $\mathrm{my}^{\circ}$.hh". She offers the number of questions (lines 11-12,14) and a gloss of the level of detail of the questions (lines 17, 19-20). Tom does not respond at any of Marion's points of possible completion (lines 13, 16, 18, and 21). Marion, however, had projected from the outset of her turn that she would be providing a summary of the requested "helpful information." Her turn thus can be seen as a course of action comprised of several components of information that the instructor covered with respect to the upcoming exam. It is not until the completion of her TCU in line 20 that Marion comes to full falling intonation. At this point, though, Tom still does not respond (line 21). When he does respond (line 22), he offers first an acknowledgement "Oh" and then a single token "waiit.". Subsequently, he moves from that single token into a repeat with "wait=wait." His initial TCU, then, first claims a change of state with "Oh" (Heritage, 1984a) and then requests Marion to "wait.". Given that this comes after a 1.3 second silence, the question of why he is requesting that she "wait" is not insignificant. One account for the silence here is that Marion has inadequately projected that this concludes her "helpful information" about the exam. She has brought this turn to final intonation; however, she has provided only one example, and the information she has given is minimal. It is also possible that Marion is unsure whether she should continue or whether Tom may be taking notes (though Tom has done no vocal work to display this to be occurring).

Regardless of the account for the silence, the larger question may be the fit between a multiple saying designed to halt an in-progress action and a course of action that appears to be halted with a substantial delay. Similar to other multiples, the answer appears to be that Tom is working to address the prior course of action rather than the just prior silence, or the just prior turn. The use of a single item "wait" is ill-fitted here precisely because of the silence. On the other hand, the use of a multiple saying reframes his in-progress turn as addressing Marion's larger course of action. As seen, multiple sayings are a resource for reaching back in interaction: here that involves reaching across a silence. Tom's transformed multiple thus projects that the problem to come is with the larger informing (lines 10-20), not with the "level of detail" component of her informing (lines 19-20). The question he then asks "what kinda questions. are they multiple choice? O:r" (lines 22-23) seeks information about the test at a fundamentally more basic level than Marion had been providing. 
The problem with Marion's course of action thus is that, overall, the level of granularity is too fine rather than that the last component alone was problematic.

In this example, a speaker shifts from the use of a single token to a multiple saying in an effort to reframe his talk as addressed to the prior course of action. This provides further evidence that speakers are oriented to the practice of multiple sayings as discrete from the use of single tokens and further evidence for the function of multiple sayings in such contexts.

\section{DISCUSSION}

This article has described the interactional practice of multiple sayings that are done by the same speaker, involve a full unit of talk, have a similar segmental character, and are done immediately in succession and under a single intonation contour. The practice of multiple sayings can involve a wide range of lexical items, phrases, and sentences, and the practice appears to involve repeats from two to seven in number with longer items typically being repeated fewer times. ${ }^{9}$ The practice of multiple sayings was shown to be systematic in its positioning and in its function across several languages.

As an instance of an identification and description of a systematic interactional practice in ordinary conversation, this article contributes to literature within the conversation analytic tradition across the fields of communication, linguistics, and sociology. In particular, this article shows that multiple sayings are an interactional resource for speakers to display their talk as addressed to a larger course of action rather than only to the just prior unit of talk. Much of this understanding of how sequences are organized focuses on the relationships between adjacent turns. At the same time, speakers also understand sequences of talk to comprise larger courses of action and have resources for addressing these larger organizational packages. Multiple sayings function to display that the speaker finds the prior speaker's course of action problematic, typically its perseveration, and proposes that that course of action be halted.

This practice also has implications for understanding the role of prosody in interaction. In contrast to the ways in which prosody has been observed to manage turn transfer across transition relevance places (Auer, 1996; Schegloff, 1982), the practice outlined here suggests that speakers use the intonation contour as a resource for building the turn as comprised of only one TCU and thus as not having transition relevance places within it. Here prosody is thus a resource for projecting from the outset of the turn that a multiple saying is in progress. This suggests that speakers 
may have prosodic resources that can override syntactic boundaries (e.g., phrasal or sentential boundaries) not only at or near transition relevance places as discussed by Schegloff (1982) and Auer (1996) but also at turn beginning.

\section{APPENDIX}

\section{Transcript Symbol}

1. Temporal and sequential relationships

A. Overlapping or simultaneous talk is indicated in a variety of ways. Separate left square brackets-

[

-one above the other on two successive lines with utterances by different speakers, indicates a point of overlap onset, whether at the start of an utterance or later.

Separate right square brackets-

]

]

-one above the other on two successive lines with utterances by different speakers, indicates a point at which two overlapping utterances both end, where one ends while the other continues, or simultaneous moments in overlaps which continue.

B. Equal signs (=) ordinarily come in pairs-one at the end of a line and another at the start of the next line or one shortly thereafter. They are used to indicate three things:

1) If used between two words by one speaker with no break in the transcription, this indicates that the words/sounds were produced so as to sound latched.

2) If the two lines connected by the equal signs are by the same speaker, then there was a single, continuous utterance with no break or pause, which was broken up in order to accomodate the placement of overlapping talk.

3) If the lines connected by two equal signs are by different speakers, then the second followed the first with no discernable silence between them, or was "latched" to it.

C. Numbers in parentheses indicate silence, represented in tenths of a second. For example: (0.5) indicates 5/10 seconds of silence. Silences may be marked either within an utterance or between utterances.

D. A dot in parentheses-

(.)

—indicates a "micropause," hearable but not readily measurable (ordinarily less than $2 / 10$ of a second).

2. Aspects of speech delivery, including aspects of intonation.

A. The punctuation marks are not used grammatically, but to indicate intonation. The period (.)indicates a falling, or final, intonation contour, not necessarily the end of a sentence. Similarly, a question mark (?) indicates rising intonation, not necessarily a question, and a comma (,) indicates "continuing" intonation, not necessarily a clause boundary. A combined question mark and comma (?,) indicates a rise stronger than a comma but weaker than a question mark. An underscore (_) following a unit of talk indicates level intonation. The semicolon (;) indicates that the intonation is equivocal between final and "continuing." 
B. Colons (::) are used to indicate the prolongation or stretching of the sound just preceding them. The more colons, the longer the stretching.

C. A hyphen (-) after a word or part of a word indicates a cut-off or self-interruption.

D. Underlining (e.g., word) is used to indicate some form of stress or emphasis, either by increased loudness or higher pitch. The more underlining, the greater the emphasis.

E. The degree sign $\left(^{\circ}\right)$ indicates that the talk following it was markedly quiet or soft. When there are two degree signs, the talk between them is markedly softer than the talk around it.

G. The carrot $(\wedge)$ indicates a rise in pitch.

$\mathrm{H}$. The combination of "more than" and "less than" symbols $(><)$ indicates that the talk between them is compressed or rushed. Used in the reverse order $(<>)$, they can indicate that a stretch of talk is markedly slowed or drawn out. The "less than" symbol by itself $(<)$ indicates that the immediately following talk is "jump-started" (i.e., sounds like it starts with a rush).

I. Hearable aspiration is shown where it occurs in the talk by the letter " $\mathrm{h}$ " (e.g., hhh)the more h's, the more aspiration. The aspiration may represent breathing or laughter. If it occurs inside the boundaries of a word, it may be enclosed in parentheses-

(hh)

-in order to set it apart from the sounds of the word. If the aspiration is an inhalation, it is shown with a dot before it (.hh).

J. British pound signs $(£ £)$ indicate that the words following or in between are said with "smile voice."

K. Pound signs (\# \#) indicate that the wor ds following or in between are said with a creaky voice

3. Other markings.

A. Double parentheses-

$((\quad))$

- are used to mark transcriber's descriptions of events, rather than representations of them (e.g., ((cough)), ((sniff)), ((telephone rings)), ((footsteps)), ((whispered)), ((pause)) as descriptions).

B. When all or part of an utterance or the speaker identification is in parentheses-for example, (word) - this indicates uncertainty on the transcriber's part, but represents a likely possibility. Empty parentheses-

( )

-indicate that something is being said, but no hearing (or, in some cases, speaker identification) can be achieved.

In the Russian transcript, this symbol-

/

-indicates a unit boundary and a somewhat falling pitch contour in the absence of any other intonation marking.

\section{NOTES}

1. In general the repeated items have exactly the same segmental character. However, if there is variation this tends to be with the final or next-to-final items (e.g., see Extract 4). Another variation is that later items in a multiple saying may not be as fully articulated (e.g., compare the first and subsequent articulations of "alright" in Extract 2).

2. Other conversation analytic studies have also examined repeats by different speakers (e.g., Couper-Kuhlen, 1996; Hellerman, 2003; Schegloff, 1996; Sorjonen, 1996; Tarplee, 1996). 
3. Here, "scrape it off" appears to be an instance of transition space repair (Schegloff, Jefferson, \& Sacks, 1977). It hearably replaces a component of the turn that had been brought to completion.

4. Note that latching here indicates that the final sound of the previous word and the first sound of the next word are run together. It does not necessarily mean that the turn is spoken quickly or is otherwise being rushed. As mentioned earlier, the prosodic profile of this practice includes no break in phonation. In some cases the items are said quickly; in other cases they are run together. This, however, is not always the case. Items can be produced steadily with no break in phonation but without any latching sounds. For instance, see Extract 3. In Extract 2, the quickness of the repeats increases over the course of the turn, but this is likely responsive to Bob's having not yet abandoned his turn (line 2).

5. In a comparison of auditory and acoustic analysis of intonation unit boundaries, Schuetze-Coburn, Shapley, \& Weber (1991) found that 99\% of acoustic unit boundaries coincided with auditory unit boundaries.

6. This may be a reflection of linguistic research findings that English tone-units are typically no more than seven words (Crystal, 1969). Multiple sayings involving lengthy phrases or sentences under a single intonation contour may not often be produced-at least not in English.

7. At this point in this research, no evidence is presented that two-item repeats are produced or responded to differently from longer repeats. It may be that the number of tokens has to do with the strength or intensity of the action, though this would need to be investigated in its own right.

8. All multiple sayings are not delivered in overlap (and in fact it is possible for them to be delayed as in Extract 18); however, this does not take away from the fact that the action multiple sayings are doing is further enhanced by the overlap. That is, multiple sayings delivered in overlap may more strongly convey their stance towards the prior turn as persisting in an unwarranted course of action.

9. Seven repeats is the highest number observed in a multiple saying.

\section{REFERENCES}

Auer, P. (1996). On the prosody and syntax of turn-continuations. In E. Couper-Kuhlen \& M. Selting (Eds.), Prosody in conversation (pp. 57-100). Cambridge, UK: Cambridge University Press.

Beach, W. A. (1995). Preserving and constraining options: "Okays" and "official" priorities in medical interviews. In B. Morris \& R. Chenail (Eds.), Talk of the clinic: Explorations in the analysis of medical and therapeutic discourse (pp. 259-290). Hillsdale, NJ: Erlbaum.

Chafe, W. (1980). The Deployment of Consciousness in the production of a narrative. In W. Chafe (Ed.), The pear stories: Cognitive, cultural, and linguistic aspects of narrative production (pp. 9-50). Norwood, NJ: Ablex.

Chafe, W. (1987). Cognitive constraints on information flow. In R. Tomlin (Ed.,) Coherence and grounding in discourse (pp. 21-51). Amsterdam: Benjamins.

Clark, H. H. \& Wasow, T. (1998). Repeating words in spontaneous speech. Cognitive Psychology, 37(3), 201-242.

Couper-Kuhlen, E. (1996). The prosody of repetition: on quoting and mimicry. In E. CouperKuhlen \& M. Selting (Eds.), Prosody in conversation (pp. 366-405). Cambridge, UK: Cambridge University Press.

Couper-Kuhlen, E. (2001.) Interactional prosody: High onsets in reason-for-the call turns. Language in Society, 30(1), 29-53. 
Crystal, D. (1969). Prosodic systems and intonation in English. Cambridge, UK: Cambridge University Press.

Crystal, D. \& Quirk, R. (1964). Systems of prosodic and paralinguistic features in English. The Hague: Mouton.

Drew, P. (1997). 'Open' class repair initiators in response to sequential sources of troubles in conversation. Journal of Pragmatics, 28(1), 69-101.

Duncan, S., Jr. \& Fiske, D. W. (1977). Face-to-face interaction: Research, methods, and theory. New York: Wiley.

Ford, C. E. (1993). Grammar in Interaction: Adverbial clauses in American English conversations. Cambridge, England: Cambridge University.

Ford, C. E. \& Thompson, S.A. (1996). Interactional units in conversation: syntactic, intonational and pragmatic resources for the management of turns. In E. Ochs, E. A. Schegloff, \& S. A.Thompson (Eds.) Interaction and grammar (pp. 134-184). Cambridge, UK: Cambridge University Press.

Goffman, E. (1983). The interaction order. American Sociological Review , 48, 1-17.

Hellerman, J. (2003) The interactive work of prosody in the IRF exchange: Teacher repetition in feedback moves. Language in Society, 32(1), 79-104.

Heritage, J. (1984a). A change-of-state token and aspects of its sequential placement. In J. M. Atkinson \& J. Heritage (Eds.), Structures of social action (pp. 299-345). Cambridge, UK: Cambridge University Press.

Heritage, J. (1984b). Garfinkel and ethnomethodology. Cambridge, UK: Polity.

Heritage, J. \& Atkinson, J.M. (1984). Introduction. In J. M. Atkinson and J. Heritage (Eds.), Structures of social action (pp. 1-16). Cambridge, UK: Cambridge University Press.

Levelt, W. (1989). Speaking: From intention to articulation. Boston: MIT Press.

Müller, F. E. (1996) Affiliating and disaffiliating with continuers: prosodic aspects of recipiency. In E. Couper-Kuhlen \& M. Selting (Eds.), Prosody in conversation (pp. 131176). Cambridge, UK: Cambridge University Press.

Pierrehumbert, J. (1980). The phonology and phonetics of English intonation. Unpublished doctoral dissertation, Massachusetts Institute of Technology, Cambridge.

Sacks, H., Schegloff, E. A. \& Jefferson, G. (1974). A simplest systematics for the organization of turn-taking for conversation. Language, 50, 696-735.

Schegloff, E. A. (1982). Discourse as an interactional achievement: Some uses of 'uh huh' and other things that come between sentences. In D. Tannen (Ed.), Analyzing discourse (Georgetown University Roundtable on Languages and Linguistics 1981) (pp. 71-93). Washington DC: Georgetown University.

Schegloff, E. A. (1987). Recycled turn beginnings: A precise repair mechanism in conversation's turn-taking organisation. In G. Button \& J. R. E. Lee (Eds.), Talk and social organisation (pp. 70-85). Clevedon, UK: Multilingual Matters.

Schegloff, E. A. (1992). Repair after next turn: The last structurally provided for place for the defense of intersubjectivity in conversation. American Journal of Sociology, 95(5), 1295-1345.

Schegloff, E. A. (1996). Confirming allusions: toward an empirical account of action. American Journal of Sociology, 104(1), 161-216.

Schegloff, E. A. (2001, July). Increments: What they are and what they do. Lecture given at the Linguistic Summer Institute, Santa Barbara, CA.

Schegloff, E. A. (in press). A primer for conversation analysis: Sequence organization. Cambridge, UK: Cambriddge University Press.

Schegloff, E. A., Jefferson, G. \& Sacks, H. (1977). The preference for self-correction in the organization of repair in conversation. Language, 53, 361-382.

Schegloff, E. A. \& Sacks, H. (1973). Opening up closings. Semiotica, 8, 289-327.

Schuetze-Coburn, S., Shapley, M. \& Weber, E. G. (1991). Units of intonation in discourse: acoustic and auditory analyses in contrast. Language and Speech, 34, 207-234. 
Shimanoff, S. \& Brunak, J. (1977). Repairs in planned and unplanned discourse. In E. Keenan and T. Bennett (Eds), Discourse across time and space (pp. 123-167). Los Angeles: University of Southern California.

Sorjonen, M. (1996). Repeats and responses in Finnish conversations. In E. Ochs, E. A. Schegloff, \& S. A. Thompson (Eds.), Interaction and grammar (pp. 277-327). Cambridge, England: Cambridge University Press.

Tannen, D. (1989). Talking voices: Repetition, dialogue, and imagery in conversational discourse. Cambridge, UK: Cambridge University Press.

Tarplee, C. (1996) Working on young children's utterances: Prosodic aspects of repetition during picture labeling. In E. Couper-Kuhlen \& M. Selting (Eds.), Prosody in conversation (pp. 406-435). Cambridge, UK: Cambridge University Press.

Wong, J. (2000). Repetition in conversation: A look at "First and second sayings." Research on Language and Social Interaction, 33(4), 407-424. 